\title{
Extraction of some secondary metabolites \& thin layer chromatography from different parts of Centella asiatica L. (URB)
}

\author{
Sanjay R. Biradar, Bhagyashri D. Rachetti \\ Tissue Culture Laboratory, Department of Botany, Shri Chhatrapati Shivaji College Omerga - 413606, Dist. Osmanabad, (MS).INDIA
}

Email address:

sanjaybiradar2006@rediffmail.com (S. R. Biradar), rachettib@gmail.com (B. D. Rachetti)

\section{To cite this article:}

Sanjay R. Biradar, Bhagyashri D. Rachetti. Extraction of Some Secondary Metabolites \&Thin Layer Chromatography from Different Parts of Centella Asiatica L. (URB). American Journal of Life Sciences. Vol. 1, No. 6, 2013, pp. 243-247.

doi: 10.11648/j.ajls.20130106.11

\begin{abstract}
Centella asiatica (L.) Urb. known as Brahmi, Indian Pennywort and Mandookaparni is a small herbaceous annual plant of the family Apiaceae, It is used in traditional medicine for the treatment of various ailments \& ayurvedic treatment for many diseases. Present study deals with the qualitative and quantitative analysis of ethanolic extract of root, stem \& leaf of Centella asiatica (L.) Urb. A qualitative analysis by thin layer chromatography \& a quantitative analysis by standard chemical protocol of secondary metabolites in the root, stem and leaf of the Centella asiatica L. (URB) have been studied. Using thin layer chromatography (TLC) different components like Alkaloids, Saponin, Flavonoids, Terpenoides, Phenol \& Tannin are isolated \& identified. The $\mathrm{R} f$ values of the developed spots in the different solvent systems are noted. In the quantitative analysis, alkaloids, saponins, terpenoids \& flavonoids are extracted by using the standard chemical protocol. These results may be helpful for rationale use of this plant in the modern system of health care.
\end{abstract}

Keywords: Centella Asiatica L. Quantitative Analysis, TLC

\section{Introduction}

Plants are endowed with various phytochemical molecules such as vitamins, terpenoids, phenolic acids, lignins, stilbenes, tannins, flavonoids, quinones, coumarins, alkaloids, amines, betalains, and other metabolites, which are rich in antioxidant activity [1] [2]. Studies have shown that many of these antioxidant compounds possess anti-inflammatory, antiatherosclerotic, antitumor, antimutagenic, anticarcinogenic, antibacterial, and antiviral activities [3] [4]. The ingestion of natural antioxidants has been associated with reduced risks of cancer, cardiovascular disease, diabetes, and other diseases associated with ageing [5] [6] and in recent years, there has been a worldwide trend towards the use of the natural phytochemicals present in berry crops, teas, herbs, oilseeds, beans, fruits and vegetables [7] [9]. Centella asiatica (Linn.) Urban sys. synonym Hydrocotyle asiatica Linn. It is one of the chief herbs for treating skin problems, to heal wounds, for revitalizing the nerves and brain cells, hence primarily known ass a "Brain food" in India[10].The scientific studies have proved a variety of biochemical components i.e. secondary metabolites have been found in Centella asiatica. The chemical constituents of Centella plant have a very important role in medicinal and nutraceutical applications and it is believed due to its biologically active components of triterpenes saponins[11].

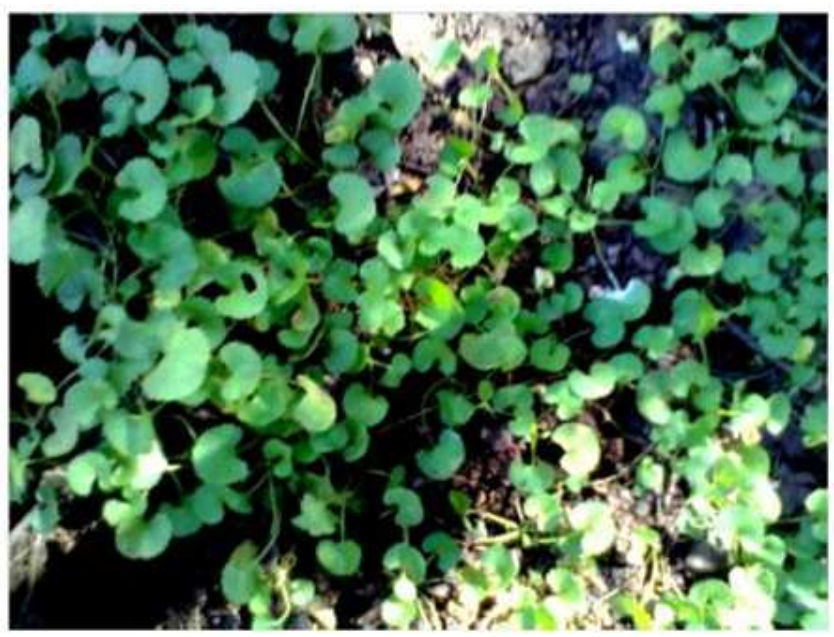

Photo Plate 1: Vegetation of Centella asiatica L. 
Centella asiatica of Apiaceae family is widely used for its medicinal properties like sedative, analgesic, antidepressive, antimicrobial, antiviral and immunomodulatory[12]. The triterpenes of Centella are composed of many compounds including asiatic acid, madecassic acid, asiaticosside, madecassoside, brahmoside, brahmic acid, brahminoside, thankiniside, isothankunisode, centelloside, madasiatic acid, centic acid, and centellicacid[13].

\section{Material and Methods}

\subsection{Study Area}

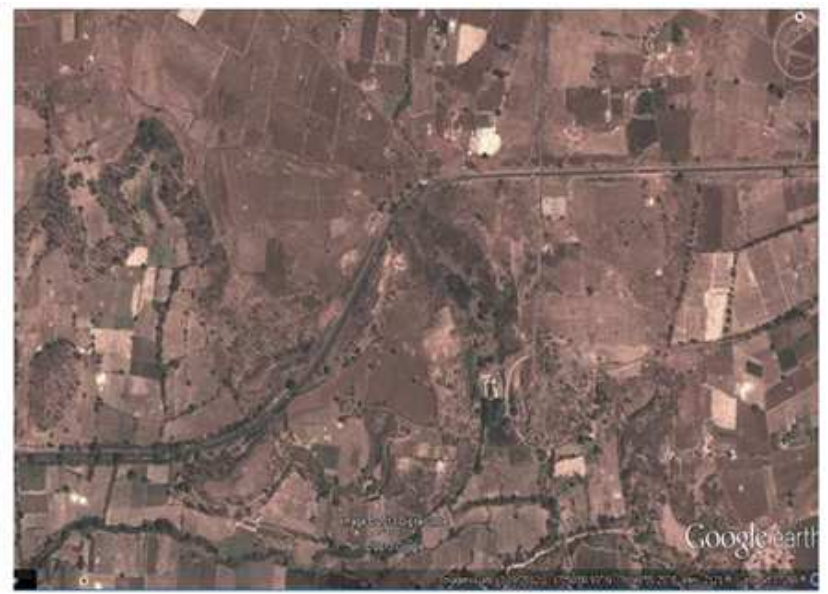

Photo plate 2: Collection site - Amrutkund Tq. Basavkalyan, Dist. Bidar near Maharashtra-Karnataka border.

Study area, Amritkund (Dist. Bidar) lies between 17 o 49

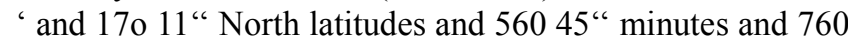
49' east longitudes, with the districts of Nizamabad and Medak in Andhra Pradesh on the East and the districts of Nanded and Osmanabad in Maharashtra on the west. On the south lies the district of Gulbarga of Karnataka.

\subsection{Collection of Plant Materials}

The fresh parts of Centella asiatica (L.) Urb. were collected in flowering period from Amrutkund Tq. Basavkalyan, Dist. Bidar near Maharashtra-Karnataka border. The plant material were properly washed with tap water and then rinsed with distilled water, dried in oven at $60^{\circ} \mathrm{C}$ until plant parts became well dried for grinding. After drying, the plant materials were ground well into fine powder.

\subsection{Preparation of Ethanolic Extract (Root, Stem and Leaf)}

For preparation of ethanolic extract, a modified method of Abdulrahman et.al (2004) [14] was used. The fresh parts of the plant were dried in oven and ground to fine powder with mechanical grinder. Ten gram of each plant parts was then macerated in $100 \mathrm{ml}$ of absolute ethanol for $72 \mathrm{hr}$. \& properly covered with aluminum foil \& labeled. After 72 hrs of extraction, each extract was filtered through Whatman's filter paper no.1 separately. The filtrate was evaporated to dryness at room temperature \& store at $50^{\circ} \mathrm{C}$ in refrigerator.

\subsubsection{Qualitative Analysis by thin Layer Chromatography [15]}

Extract was to begin with, checked by Thin Layer Chromatography (TLC) on analytical plates over silica gel. TLC was carried out to isolate the principle components that were present in most effective extracts of plant. The different solvent systems of different polarities were prepared and TLC studies were carried out to select the solvent system capable of showing better resolution.

\section{Method}

The above prepared plant extracts were applied on pre-coated TLC plates by using capillary tubes and developed in a TLC chamber using suitable mobile phase. The developed TLC plates were air dried and observed under ultra violet light UV at both $254 \mathrm{~nm}$ and $366 \mathrm{~nm}$. They were later sprayed with different spraying reagents and some were placed in hot air oven for $1 \mathrm{~min}$ for the development of color in separated bands. The movement of the analyze was expressed by its retention factor (Rf). Values were calculated for different sample.

$$
\mathrm{R} f=\frac{\text { Distance travel by solute }}{\text { Distance travel by solvent }}
$$

( $\mathrm{R} f$-Retention factor)

\section{Detection}

After drying the plates, they were exposed to Iodine vapours by placing in a chamber that was saturated with iodine vapours and also exposed to different spraying reagents. All plates were visualized directly after drying and with the help of UV at $254 \mathrm{~nm}$ and $366 \mathrm{~nm}$ in UV TLC viewer. The $\mathrm{R} f$ value of the different pots that were observed was calculated.

\subsubsection{Quantitative Analysis}

The phytochemicals which are present in the ethanol extracts of Centella asiatica were determined and quantified by standard procedures.

\subsubsection{Alkaloid Determination Using Harborne (1973) Method}

$5 \mathrm{~g}$ of the sample was weighed into a $250 \mathrm{ml}$ beaker and $200 \mathrm{ml}$ of $10 \%$ acetic acid in ethanol was added and covered and allowed to stand for $4 \mathrm{~h}$. This was filtered and the extract was concentrated on a water bath to one-quarter of the original volume. Concentrated ammonium hydroxide was added dropwise to the extract until the precipitation was complete. The whole solution was allowed to settle and the precipitated was collected and washed with dilute ammonium hydroxide and then filtered. The residue is the alkaloid, which was dried and weighed [16]. 


\subsubsection{Flavonoid Determination by the Method of Boham and Kocipai- Abyazan (1994)}

$10 \mathrm{~g}$ of the plant sample was extracted repeatedly with $100 \mathrm{ml}$ of $80 \%$ aqueous methanol at room temperature. The whole solution was filtered through whatman filter paper No $42(125 \mathrm{~mm})$. The filtrate was later transferred into a crucible and evaporated into dryness over a water bath and weighed to a constant weight [17].

\subsubsection{Saponin Determination Using Obadoni and Ochuko (2001) method}

$10 \mathrm{~g}$ of samples powder was put into a conical flask and $50 \mathrm{ml}$ of $20 \%$ aqueous ethanol were added. The samples were heated over a hot water bath for $4 \mathrm{~h}$ with continuous stirring at about $55^{\circ} \mathrm{C}$. The mixture was filtered and the residue re-extracted with another $100 \mathrm{ml} \mathrm{20 \%}$ ethanol. The combined extracts were reduced to $40 \mathrm{ml}$ over water bath at about $90^{\circ} \mathrm{C}$. The concentrate was transferred into a $250 \mathrm{ml}$ separating funnel and $10 \mathrm{ml}$ of diethyl ether was added and shaken vigorously. The aqueous layer was recovered while the ether layer was discarded. The purification process was repeated. $30 \mathrm{ml}$ of $\mathrm{n}$-butanol was added. The combined n-butanol extracts were washed twice with $10 \mathrm{ml}$ of $5 \%$ aqueous sodium chloride. The remaining solution was heated in a water bath. After evaporation the samples were dried in the oven to a constant weight and the Saponin content was calculated as percentage [18].

\subsubsection{Total Terpenoides Determination Using Ferguson (1956) Method}

$10 \mathrm{~g}$ of plant powder were taken separately and soaked in alcohol for 24 hours. Then filtered, the filtrate was extracted with petroleum ether; the ether extract was treated as total terpenoids [19].

\section{Result \& Discussion}

TLC Profiling of Plant Extracts in Different Solvent System Confirms the Presence of Diverse Group of Phytochemicals.

Table1: Phytochemical Analysis of different parts of Centella asiatica L. by Thin layer chromatography.

\begin{tabular}{cccc}
\hline $\begin{array}{c}\text { Chemical } \\
\text { Name }\end{array}$ & $\begin{array}{c}\text { Solvent } \\
\text { System }\end{array}$ & PP & Rf values \\
\hline Alkaloids & $\mathrm{M}: \mathrm{NH}_{4} \mathrm{OH}$ & $\mathrm{R}$ & $0.48,0.55$ \\
& $(17: 3)$ & $\mathrm{S}$ & 0.64 \\
& & $\mathrm{~L}$ & $0.71,0.78$ \\
& $\mathrm{C}: \mathrm{M}(18: 2)$ & $\mathrm{R}$ & $0.26,0.30,0.45,0.57,0.82$ \\
Flavonoid & & $\mathrm{L}$ & $0.16,0.20,0.26,0.33,0.36,0.48,0.51,0.57,0.82$ \\
& $\mathrm{C}: \mathrm{GA}: \mathrm{M}:$ & $\mathrm{R}$ & $0.16,0.30,0.45,0.60,0.73,0.82,0.85$ \\
Saponins & $\mathrm{S}(6: 2: 1: 1)$ & $\mathrm{L}$ & $0.10,0.76$ \\
& & $\mathrm{R}$ & 0.08 \\
B:EA & $(1: 1)$ & $\mathrm{S}$ & $0.36,0.37,0.87$ \\
& I & $0.36,0.39,0.87$ \\
\end{tabular}

Note : P P-Plant part., C-chloroform, M-methanol, B-Benzene, EA- Ethyl acetate, GA- Glacial acetate, W-water, R-root, S-stem, L-leaf,

\subsection{TLC for Alkaloid}

TLC of root extract of Centella asiatica revealed the presence of 2 compounds having $\mathrm{R} f$ values of $0.48,0.55$ respectively when a solvent phase of Methanol: $\mathrm{NH}_{4} \mathrm{OH}$ (17:3) was used. TLC of stem extract of Centella asiatica revealed the presence of 2 compounds having $\mathrm{R} f$ values of 0.64 when a solvent phase of Methanol: N H 4 OH (17:3) was used. TLC of leaf extract of Centella asiatica revealed the presence of 2 compounds having $\mathrm{R} f$ values of $0.71,0.78$ respectively when a solvent phase of Methanol: $\mathrm{NH}_{4} \mathrm{OH}$ $(17: 3)$ was used.

\subsection{TLC for Flavonoid}

TLC of root extract of Centella asiatica revealed the presence of 3 compounds having $\mathrm{R} f$ values of $0.26,0.30$, $0.45,0.57,0.82$ respectively when a solvent phase of Chloroform: Methanol (18:2) was used. TLC of stem extract of Centella asiatica revealed the presence of 3 compounds having $\mathrm{Rf}$ values of $0.16,0.20,0.26,0.33,0.36$,
$0.48,0.51,0.57,0.82$ respectively when a solvent phase of Chloroform: Methanol (18:2) was used. TLC of leaf extract of Centella asiatica revealed the presence of 5 compounds having $\mathrm{Rf}$ values of $0.16,0.30,0.45,0.60,0.73$, $0.82, \quad 0.85$ respectively when a solvent phase of Chloroform : Methanol (18:2) was used.
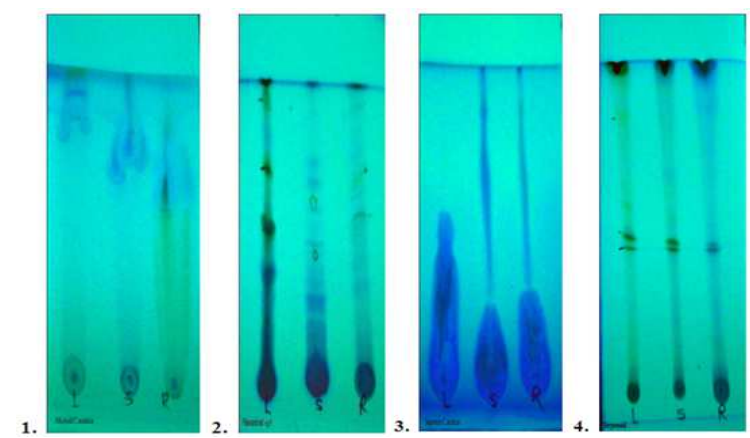

Photo plate 3: TLC of 1. Alkaloids 2. Flavonoid, 3. Terpenoides 4. Saponin of different parts of Centilla asiatica $L$. 


\subsection{TLC for Saponin}

TLC of root extract of Centella asiatica revealed the presence of 1 compound having $\mathrm{R} f$ values of 0.22 when a solvent phase of Chloroform: glacial acetic acid: methanol: water $(6: 2: 1: 1)$ was used. TLC of stem extract of Centella asiatica revealed the presence of 3 compounds having $\mathrm{R} f$ values of $0.10,0.76$ respectively when a solvent phase of Chloroform: glacial acetic acid: methanol: water (6:2:1:1) was used. TLC of leaf extract of Centella asiatica revealed the presence of 5 compounds having $\mathrm{R} f$ values of 0.08 when a solvent phase of Chloroform: glacial acetic acid: methanol: water $(6: 2: 1: 1))$ was used.

\subsection{TLC for Terpenoids}

TLC of root extract of Centella asiatica revealed the presence of 3 compounds having $R f$ values of $0.36,0.37$, 0.87 respectively when a solvent phase of Benzene: Ethyl acetate (1:1) was used. TLC of stem extract of Centella asiatica revealed the presence of 3 compounds having $\mathrm{R} f$ values of $0.36,0.39,0.87$ respectively when a solvent phase of Benzene: Ethyl acetate (1:1) was used. TLC of leaf extract of Centella asiatica revealed the presence of 5 compounds having $\mathrm{R} f$ values of $0.36,0.40,0.46,0.73,0.86$ respectively when a solvent phase of Benzene: Ethyl acetate $(1: 1)$ was used.

TLC profiling of all extracts gives an impressive result that directing towards the presence of number of phytochemicals. Various phytochemicals gives different $\mathrm{R} f$ values in different solvent system. This variation in $\mathrm{R} f$ values of the phytochemicals provides a very important clue in understanding of their polarity.

From the earlier report knew that Centella asiatica was traditionally used for many diseases particularly the plant was identified and authenticated botanically. The Plant parts (Root, Stem and Leaf) were shade dried and ground to the coarse powder. Based upon the preliminary phytochemical test Quantitative determination phytoconstituents were carried out for the powdered plant material by various standard methods and found that alkaloid $0.01 \mathrm{gm}, 0.1$ and $0.2 \mathrm{gm}$ in root, stem, leaf respectively, flavonoids $0.1 \mathrm{gm}, 0.3 \mathrm{gm}$ and $1.4 \mathrm{gm}$ in root, stem, leaf respectively, terpenoids $0.1 \mathrm{gm}, 0.1 \mathrm{gm}$ and $0.7 \mathrm{gm}$ in root, stem, leaf resp. and Saponin $0.1 \mathrm{gm}, 0.2 \mathrm{gm}$ and $0.2 \mathrm{gm}$ in root, stem, leaf respectively.

Table 2:- Quantitative analysis of Centella asiatica $L$.

\begin{tabular}{|c|c|c|c|c|c|c|c|c|c|c|c|}
\hline 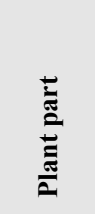 & 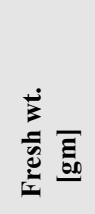 & $\stackrel{\vec{\theta}}{\vec{\theta}}$ & 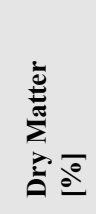 & $\begin{array}{l}\text { Alkaloid } \\
\text { In gm } \\
\text { Extraction. } \\
\text { Each } 5 \text { gm }\end{array}$ & $\begin{array}{l}\text { Alkaloid } \\
\text { [\%] }\end{array}$ & $\begin{array}{l}\text { Flavonoid. } \\
\text { [gm] } \\
\text { Extraction } \\
\text { Each 10 } \\
\text { gm }\end{array}$ & $\begin{array}{l}\text { Flavonoid } \\
\text { [\%] }\end{array}$ & $\begin{array}{l}\text { Terpenoid } \\
\text { [gm] } \\
\text { Extraction } \\
\text { Each } 10 \\
\text { gm }\end{array}$ & $\begin{array}{l}\text { Terpenoid } \\
\text { [\%] }\end{array}$ & $\begin{array}{l}\begin{array}{c}\text { Saponin } \\
\text { [gm] }\end{array} \\
\text { Extracti } \\
\text { on Each } \\
10 \mathrm{gm}\end{array}$ & $\begin{array}{l}\text { Saponin } \\
{[\%]}\end{array}$ \\
\hline Root & 41.75 & 38.8 & 92.93 & 0.01 & 0.025 & 0.1 & 0.25 & 0.1 & 0.25 & 0.1 & 0.25 \\
\hline Stem & 56.13 & 53.55 & 95.40 & 0.1 & 0.18 & 0.3 & 0.56 & 0.1 & 0.18 & 0.2 & 0.37 \\
\hline Leaves & 48.43 & 45.34 & 93.61 & 0.2 & 0.44 & 1.4 & 3.0 & 0.7 & 1.55 & 0.2 & 0.44 \\
\hline
\end{tabular}

\section{Conclusion}

In the present study leaf, stem and root showed the presence of bioactive compound such as alkaloids, flavonoids, terpenoids, saponins, etc . This study also leads to the further research in the way of isolation and identification of the active compound from the leaf, stem and root of Centella asiatica L. using chromatographic and spectroscopic techniques.

\section{Acknowledgement}

Author Dr. Sanjay Biradar, Principal Investigator is grateful thanks to UGC- New Delhi for sanctioned the Major Research Project [F.No. 41-479/2012(SR)] and also thankful to Principal of Shri Chhatrapati Shivaji College, Omerga, Dist. Osmanabad, (M.S.), India for providing all necessary facilities and encouragement for the present research work.

\section{References}

[1] Zheng W, Wang SY. Antioxidant activity and phenolic compounds in selected herbs. J Agric Food Chem 2001; 49(11): 5165-5170.

[2] Cai YZ, Sun M, Corke H. Antioxidant activity of betalains from plants of the Amaranthaceae. J Agric Food Chem 2003; 51(8): 2288-2294.

[3] Sala A, Recio MD, Giner RM, Manez S, Tournier H, Schinella G, Rios JL. Antiinflammatory and antioxidant properties of Helichrysum italicum. J Pharm Pharmacol 2002; 54(3): 365-371.

[4] Rice-Evans CA, Miller NJ, Bolwell PG, Bramley PM, Pridham JB. The relative activities of Plant-derived polyphenolic flavonoid. Free radical Res 1995; 22: 375-383.

[5] Ashokkumar D, Mazumder UK, Gupta M, Senthilkumar GP, Selvan VT. Evaluation of Antioxidant and Free Radical Scavenging Activities of Oxystelma esculentum in various in vitro Models. J Comp Integ Med 2008; 5(1): 1-6. 
[6] Veerapur VP, Prabhakar KR, Parihar VP, Kandadi MR, Ramakrishana S et al. Ficus racemosa Stem Bark Extract: A Potent Antioxidant and a Probable Natural Radioprotector. Evid Based Complement Alternat Med 2009; 6(3): 317-324.

[7] Kitts DD, Yuan YV, Wijewickreme AN, Hu C. Antioxidant properties of a North American gingseng extract. Mol Cell Biochem 2000; 20(3):1-10.

[8] Muselík J, García-Alonso M, Martín-López MP, Želmièka M, Rivas-Gonzalo JC. Measurement of Antioxidant Activity of Wine Catechins, Procyanidins, Antocyanins and Piranoantocyanins. Int J Mol Sci 2007; 8: 797-809.

[9] Wang SY, Jiao H. Correlation of antioxidant capacities to oxygen radical scavenging enzyme activities in blackberry. $\mathrm{J}$ Agric Food Chem 2000; 48: 5672-5676.

[10] Singh.S., Gautam.A, Sharma.A and Batra.A Centella asiatica (L.): A plant with immense medicinal potential but threatened, International journal of pharmaceutical sciences review and research 2010; 4(2): 9-17.

[11] Loiseau, A. and Mercier, M. Centella asiatica and skin care. Cosmetics and Toiletries Magazine 2000; 115: 63- 67.

[12] Brinkhaus B., Lindner M., Schuppan D. and Hahn E.G., Chemical, pharmacological and clinical profile of the East Asian medical plant Centella asiatica, Phytomedicine, 7(5), 427-48 (2000)
[13] Zheng, CJ. and Qin, LP. Chemical components of Centella asiatica and their bioactives. Journal of Chinese Integrative Medicine 2007; 5: 348-351.

[14] Abdulrahman F, Inyang SI, Abbah J, Binda L, Amos S, Gamaniel K (2004). Effect of aqueous leaf extracts of Irvingia gabonesis on gastrointestinal tracts of rodents. India J. Exp. Biol. 42:787-791.

[15] Harborne JB, Phytochemical methods: A Guide to Modern techniques of plants Analysis. Chapman and Hall London, UK. 1998.

[16] Harborne JB. Phytochemical methods, London. Chapman and Hall, Ltd. 1973; 49-188.

[17] Boham BA and Kocipai-Abyazan R. "Flavonoids and condensed tannins from leaves of Hawaiian Vaccinium vaticulatum and V. calycinium" Pacific Science (1974) 48: 458-463.

[18] Obdoni BO and Ochuko PO. "Phytochemical studies and comparative efficacy of the crude extracts of some Homostatic plants in Edo and Delta States of Nigeria" Global J. Pure Appl. Sci. (2001) 8: 203-208.

[19] Ferguson NM. A Text book of Pharmacognosy. Mac Milan Company, New Delhi, 1956, 191. 